\title{
Article
}

\section{Analysis of the Barriers to Wide Spread Adoption of Electric Vehicles in Shenzhen China}

\author{
Faping Wang, Jiali Yu,Peng Yang, Lixin Miao* and Bin Ye \\ Research Center for Modern Logistics, Graduate School at Shenzhen, Tsinghua University, Beijing 100084, \\ China; wfp13@mails.tsinghua.edu.cn; happyyujiali@163.com; yang.peng@sz.tsinghua.edu.cn; \\ ye.bin@tsinghua.edu.cn \\ * Correspondence: lxmiao@tsinghua.edu.cn; Tel.: +86-755-26036773
}

\begin{abstract}
China planned to promote the large-scale adoption of Electric Vehicles (EVs) in the thirteenth five-year plan, however, this target faces many obstacles. This paper was trying to analyze the main barriers to widespread adoption of EVs through a survey in Shenzhen, which has the biggest EVs market share in China major cities. Based on previous scholarly findings, this paper conducted a new study which collected 406 approved questionnaires among 500 participants. The study proposed five hypotheses to examine the main barriers to widespread adoption of EVs. The analysis conducted by statistical methods: two-way frequency tables, chi-square test, and factor analysis. The results noted that perception of EVs advantages and recharging access remained the main barriers to EVs large-scale penetration. Besides, financial incentives drop would not cause a significant decline of EVs adoption in future. The study proposed suggestions to carmaker and government policy administrator on the analysis and discussion.
\end{abstract}

keyword: EVs; PHEVs; Penetration; Adoption; Barriers; Preference; Willingness; Attitude

\section{Introduction}

There are four types classify on EVs according to their fuel technologies: plug-in hybrid electric vehicles (PHEVs), extended-range battery electric vehicles (E-REVs), battery electric vehicles (BEVs) and hybrid electric vehicles (HEVs)[1]. Relating to EVs, ICEVs represent abbreviation of traditional internal combustion engine vehicles.

It has proposed that EVs is a good solution for the problem of transport GHG (greenhouse gas) and air pollutant emissions[2]. Most of the developed countries have been carrying out variety public policies and financial incentives for EVs large-scale adoption[11]. In the existing literature, many researchers focus on the topics of consumers' choice decision, recharging station placement and economic analysis of EVs promotion[2-10].

Despite there is a broad consensus on EVs large-scale adoption in the world, however, the benefits and realize finally falls on the consumers' willingness to accept the new technology[2]. According to a survey conducted in $2008,69 \%$ of US consumers have little or no familiarity with PHEVs technology[3]. A later research also shows that people could not accept premiums for EVs Adoption[4]. To fully understand the consumer's choice behavior, another survey study conducted in the major United States (U.S.) big cities, which examined consumer's willingness and attitudes toward plug-in electric cars[5]. The result reveals that overall ratio of desired to buy or lease electric vehicles is small. However, the interest in PHEVs technology is greater than EVs[5]. Further, it is considering that range anxiety is a barrier to EVs spread adoption[2-10], several researchers infer that people have little willingness to choose EVs because of range anxiety and inconvenient recharging access[2-10].

Many previous kinds of literature analyzed consumer's opinion, desire and attitude toward EVs[1,6-10], which also examines some other society or psychology influencing on EVs spread adoption[7]. Besides, the previous study also suggests that EVs spread adoption influenced by public policies, financial incentives, and energy price as well[9,11]. Also, many previous studies aimed to investigate consumers' pro-environmental lifestyle, technology oriented lifestyle and openness to change[6,7], Another survey research conducted to explore consumers' environment awareness, 
technology views, experiences and interests on $\operatorname{EVs}[7,8]$. As we know, China is the second biggest market for carmakers in the world, however, no much studies on the behavior of Chinese consumers for electric cars. This study will be as an extending of previous research according to a new survey in Shenzhen of China.

China has become as the largest cars producer and the second largest consumption market of passenger vehicles in the world since 2009. The demographic data published by the government shows that EVs market share of China has exceeded the United States, the production and sales data issued from website news on August thirteenth of 2015[10]. Meanwhile, it is well-known that Shenzhen is the most innovative city and EVs demonstration town in China, which has significant contribution in innovation and the openness of the global market. It is valuable to study EVs adoption status and consumers buying behavior on EVs in Shenzhen. Besides, the previous research shows there are significant differences exist in decision-making and values between Western people and Chinese[12]. Some other results of research indicates that Netherlands consumers pay high attention to value and safety[13]. The French favor design, style, and fashion in car advertisement[13]. German and Italian consumers have a similar characteristic with French, they prefer fast, advanced technology and smart and multifunction vehicles[13]. In contrast, American consider cars as a symbol of status and hunt big and powerful vehicles[13]. How about Chinese consumptions behavior toward EVs? This study did a survey among Shenzen residents, the significant contribution of which is that participants have at least three to ten years of driving experiences and they are acutely aware of cars and urban transport conditions. Also, at least one-third of respondent have EVs driving experience. The survey will focus on the participant's preference for EVs, willingness, and attitudes toward EVs.

For the remainder, Section 2 describes material and methods, Section 3 states data quality controls, Section 4 presents the main results of this survey and make some discussion on it, Section 5 is conclusions of this paper.

\section{Material and Methods}

This paper is aim to examine Chinese EVs consumer consumption behaviors through a questionnaire survey in Shenzhen. As the literature reviewed in the introduction, the previous researches has revealed some barriers to wide-spread adoption of EVs[1-10]. Besides, the earlier findings shows that cross-culture differences influence consumers' purchasing intention toward vehicles $[6,7,8]$. Another Chinese research also reveals that product-brand affects consumer's buying intention to vehicles significantly other than company-brand[8]. Hence, this paper proposed five hypothesis and tried to confirm it by analysis.

hypotheses \# 1: The participants showed more preference for EVs with local brand and elegant style. hypotheses\# 2: The participants' attitude toward EVs depends on the perception to EVs technology advantages comparing with ICEVs.

hypotheses\# 3: The participants buying willingness depends on EVs recharging access.

hypotheses\# 4: EVs high price is critical barrier to influence the participants' purchasing willingness. hypotheses\# 5: Consumers' purchasing willingness will decrease with financial subsidies drop significantly.

To examine these hypotheses, the survey conducted among residents in Shenzhen which effort to develop new energy products such as EVs, PHEVs, and solar power products. BYD-a well-known EVs producer in China, which have diversity types of EVs selling in global market. BYD EVs products covering electric passenger car, electric bus and electrical engineering vehicles such as BYD K9, electronic Van T5 and electric truck T7. Besides, total miles of EVs running in Shenzhen already achieved 150 million kilometers[15]. There were at least one thousand electric taxis, and three thousand electric buses are operating in Shenzhen during the past three years[15]. Hence, Shenzhen residents have a shorter distance to close EVs. Although Shenzhen owns a population of 1,178,900, the registered population was only3,549,900 from Shenzhen government published data. Most of others residents come from different provinces of China. Thus, the study chooses Shenzhen residents 
as a research target which was good representatives of regular status instead of a particular case.

The study collected survey data among Shenzhen residents including EVs experienced drivers, EVs consumers or residents who were familiar with EVs. This research recruited the participants and expressed the study value and contribution to them by social-medium. Each participant can received 100RMB bonus as nominal compensation. A total of 500 questionnaires were distributed in this study. Finally, 406 usable cases with a response rate of $81.2 \%$ were collected.

The study used statistics methods including Two-way frequency tables, chi-square, Fisher test and factor analysis to examine the differences between causes and consumers willingness. In the chi-square test and fisher-test, the study used standard 5 percent or 0.05 cut-off for defining the significant difference. An associated p-value less than 0.05 showed there was the significant difference[7]. Further, the study also conducted a factor analysis to explore the relationship between causes and dependent variables by IBM SPSS software. The following sections presented the survey and statistics result based on these methods.

\section{Data and Control}

We abandoned some questionnaires that participants did not response in the survey. Besides, a preliminary test showed the questionnaire need at least ten minutes with the fastest speed to complete. The mean value of time spent was seventeen minutes, and four questionnaires were removed because time spent less than three minutes. There were fifty-two items composed of the survey which was normal multi-choice style (e.g., not at all, a little, somewhat, a lot). In order to do statistical analysis specifically, the questionnaire answer choice were scored depending on the degree ("not at all": scored 1 , "a little ": scored 2 , "somewhat": scored 3 , "a lot":scored 4 ).

The survey were categorized into four sections:

I.Basic Information: age, gender, income, education, occupation, driving experiences, home ownership and travel pattern.

II. Preference for EVs: EVs characteristics pursued by consumers.

III. Purchasing willingness and attitude toward EVs: present consumer's real willingness and attitude toward EVs

IV. Public policy and financial incentives: present the main public policy and financial incentives established in China currently.

\section{4. results}

\subsection{Sample Description and Basic information}

The research target was aim to examine the consumers' buying willingness, attitudes toward EVs, and to reveal the main barriers to widespread adoption of EVs in China. Besides, the study results could be as a reference for public policy maker in some other cities in China.

The survey collected 406 usable questionnaires. Males respondents accounted for $76.4 \%$ of the whole population $(n=310), 23.6 \%$ of participants were females $(n=96)$. Respondents age mainly concentrated between 22 to 35 years old. The percentage accounted for $53.4 \%$ of the whole population. Over 35 years old group accounted for $45.5 \%$ and ranked the second position. Only 5 participants less than 22 years old.

With the occupation of the respondents, most of them were office workers which occupied $40.4 \%$ of the total participants. Private firms owners ranked in second, the Senior manager's group following. Besides, $9.4 \%$ of members were research and design engineers. The rest were students in the university. The overall sample population represents EVs potential consumers. The demographic distribution showed in Table 1 
Table 1. Sample Description

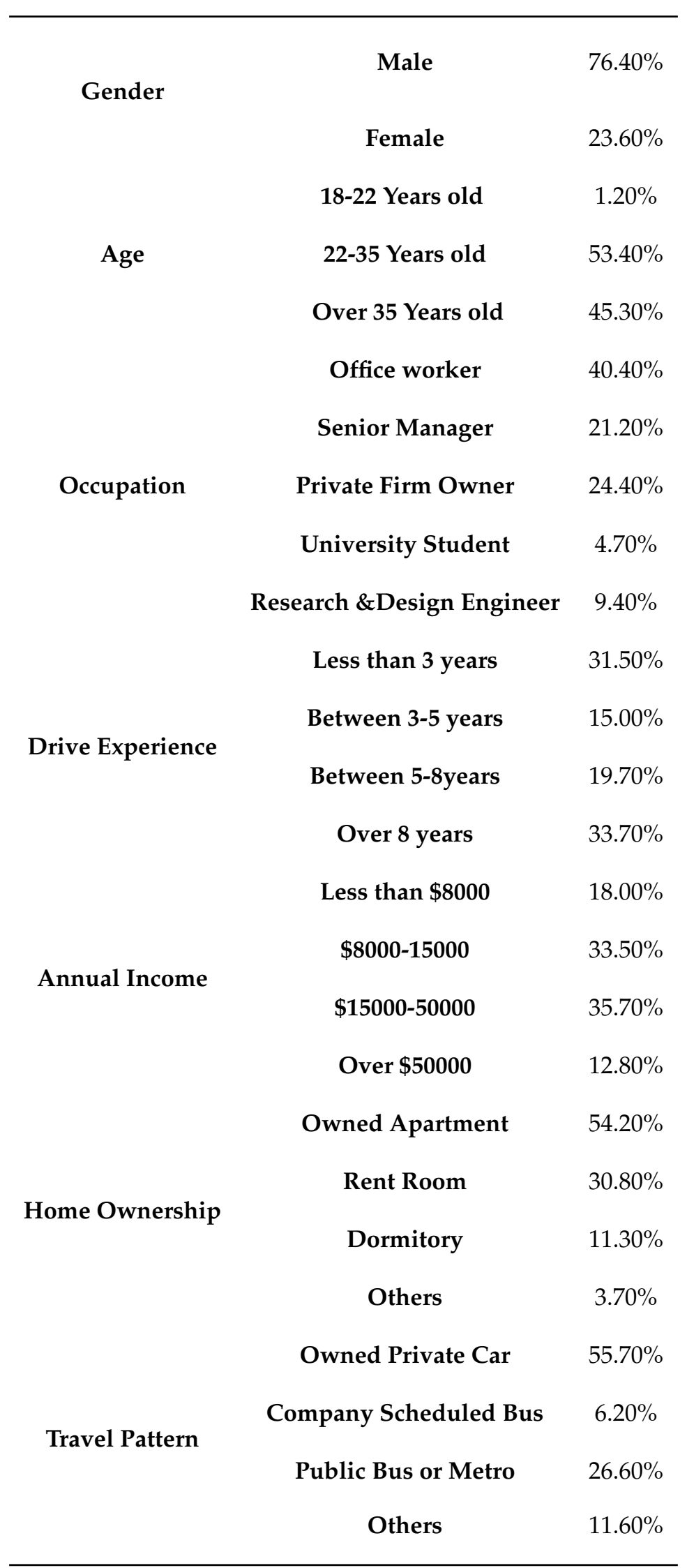


Besides, the survey summarized the respondents' driving experiences, income level, home ownership and trip pattern. Most survey respondents owned private cars and apartments. By annual revenues, more than $50 \%$ survey respondents placed at the middle or even the middle high-level in China. Also, one-third of survey respondents had driving experiences with EVs or PHEVs.

\subsection{The Preference for EVs}

Overall, according to the basic statistical analysis with Figure 1,59.3\% ( $\mathrm{n}=242)$ members showed more preferred to Chinese brand, $17.9 \%(\mathrm{n}=73)$ participants preferred to Germany EVs brand. Also, the following was $15.9 \%(\mathrm{n}=65)$ respondents aspired to United States EVs brand, and the rest was $6.9 \%(n=28)$ participants chose Japan EVs brand. Besides, Fisher's test results ( $\mathrm{p}$-value $=0.007)$ revealed there were significant differences between gender and consumers' preference for EVs brand. Males expressed more interest in Chinese EVs brand while females implied preferred to Germany EVs brand. The further Fisher's test $(\mathrm{p}$-value $=0.004$ ) revealed that $68.3 \%$ office worker and $65.8 \%$ Research and Design (R\&D) engineers preferred to chose Chinese EVs brand. Private firm owner and senior manager had similarly prefer to EVs brand of China, and the part accounted for $57.6 \%$ and $47.6 \%$ respectively. For car style, males showed more prefer to sport utility vehicle (SUV) PHEVs than females, and females implied more interest in hatchback car than men.

Table 2. Fisher Test Between Factors and Brand Preference

\begin{tabular}{rcc}
\hline Factors & Pearson Chi-Square Sig. & Fisher's Exact Test Sig. \\
\hline Occupation & 0.004 & 0.004 \\
Gender & 0.013 & 0.007 \\
\hline
\end{tabular}

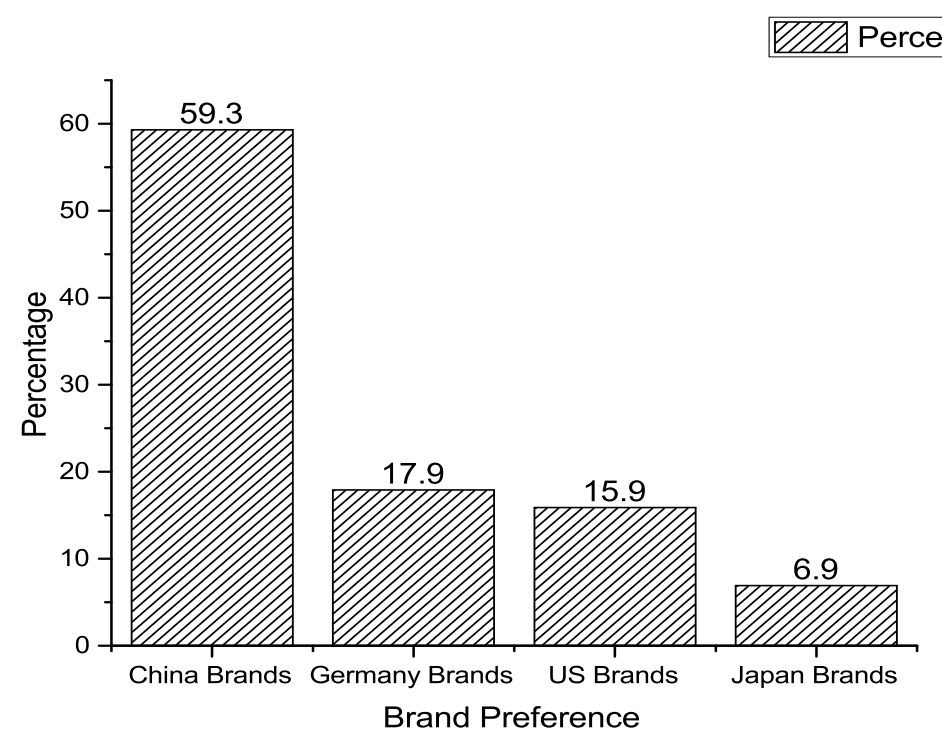

Figure 1. Brand Preference Analysis Demographic

As showed in Figure 2, 55.7\% of the participants had private cars, $68.4 \%(\mathrm{n}=279)$ surveyed respondents had EVs driving experiences. The Fisher tests ( $\mathrm{p}$-value $=0.029)$ showed little differences between gender and EVs experience, and males showed more EVs experiences than females. Besides, no significant differences between driving experience and factors such as age ( $\mathrm{p}$-value $=0.654$ ), income level ( $p$-value=0.318), occupation ( $p$-value=0.135), home ownership ( $p$-value=0.214) and 
region $(\mathrm{p}$-value $=0.463)$. However, there are significant differences between driving experience and perception of EVs (p-value $=0.006)$.

Table 3. Fisher Test Between Variables and EVs Driving Experiences

\begin{tabular}{ccc}
\hline Factors & Pearson Chi-Square Sig. & Fisher's Exact Test Sig. \\
\hline Gender & 0.039 & 0.029 \\
Perception of EVs & 0.008 & 0.006 \\
Age & 0.582 & 0.643 \\
Income level & 0.321 & 0.317 \\
Occupation & 0.132 & 0.135 \\
Home Ownership & 0.224 & 0.214 \\
Origion & 0.07 & 0.07 \\
\hline
\end{tabular}

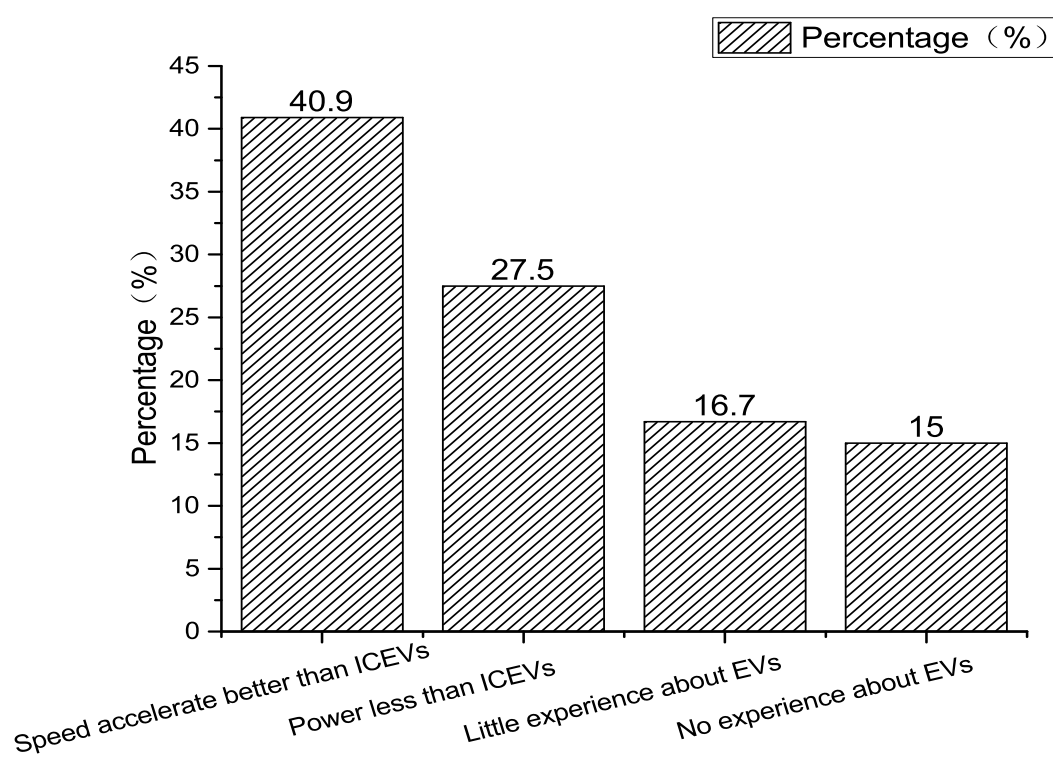

Figure 2. EVs Driving Experiences

Also, the study analyzed the primary factors by SPSS, and the results showed by Table 4 , Table 5, Figure 3 and Table 6. The research inferred the common items presented in Table 6. It offered common factors which absolute value greater than 0.5 and sorted as below:

I.Environment awareness and energy security: Respondents have high awareness of environment protection.

II.Private car demand: Real consumers desire to buy car for transport need

III.EVs Operation cost: Consumer's travel cost monthly.

IV.EVs Characteristics: Low operation cost, zero tailpipe emissions, symbol of status, etc..

V.Daily travel mileage: Consumer's travel mileage every day.

Besides, to examine the associations between consumers' preference and factors specifically, the study conducted a regression by SPSS (Statistical Products and Service Solutions). The regression residual distribution test presented as Figure 3, which showed the regression equation was valid. 
Table 4. Factor Analysis Test of EVs Purchasing Preference

\begin{tabular}{llr}
\hline \multicolumn{3}{c}{ KMO and Bartlett's Test } \\
\hline Kaiser-Meyer-Olkin Measure of Sampling Adequacy. & .684 \\
& Approx. Chi-Square & 578.781 \\
Bartlett's Test of Sphericity & df & 105 \\
& Sig. & .000 \\
\hline
\end{tabular}

Table 5. Total Variance of Principal Components

\begin{tabular}{|c|c|c|c|c|c|c|c|c|c|}
\hline \multirow[b]{2}{*}{ Component } & \multicolumn{3}{|c|}{ Initial Eigenvalues } & \multicolumn{3}{|c|}{ Extraction Sums of Squared Loadings } & \multicolumn{3}{|c|}{ Rotation Sums of Squared Loadings } \\
\hline & Total & $\%$ of Variance & Cumulative $\%$ & Total & $\%$ of Variance & Cumulative \% & Total & $\%$ of Variance & Cumulative $\%$ \\
\hline 1 & 2.589 & 17.262 & 17.262 & 2.589 & 17.262 & 17.262 & 1.912 & 12.748 & 12.748 \\
\hline 2 & 1.580 & 10.533 & 27.795 & 1.580 & 10.533 & 27.795 & 1.677 & 11.183 & 23.930 \\
\hline 3 & 1.292 & 8.611 & 36.406 & 1.292 & 8.611 & 36.406 & 1.439 & 9.593 & 33.523 \\
\hline 4 & 1.119 & 7.463 & 43.869 & 1.119 & 7.463 & 43.869 & 1.384 & 9.228 & 42.751 \\
\hline 5 & 1.020 & 6.803 & 50.672 & 1.020 & 6.803 & 50.672 & 1.188 & 7.921 & 50.672 \\
\hline 6 & .967 & 6.447 & 57.119 & & & & & & \\
\hline 7 & .881 & 5.874 & 62.993 & & & & & & \\
\hline 8 & .862 & 5.747 & 68.739 & & & & & & \\
\hline 9 & .851 & 5.675 & 74.414 & & & & & & \\
\hline 10 & .823 & 5.490 & 79.904 & & & & & & \\
\hline 11 & .745 & 4.967 & 84.870 & & & & & & \\
\hline 12 & .657 & 4.379 & 89.250 & & & & & & \\
\hline 13 & .601 & 4.008 & 93.258 & & & & & & \\
\hline 14 & .537 & 3.581 & 96.839 & & & & & & \\
\hline 15 & .474 & 3.161 & 100.000 & & & & & & \\
\hline
\end{tabular}

Table 6. Rotated Components Matrix

\begin{tabular}{lccccc}
\hline \multicolumn{5}{c}{ Component } \\
\hline & 1 & 2 & \multicolumn{1}{c}{3} & \multicolumn{1}{c}{4} & \multicolumn{1}{c}{5} \\
Q9 & .534 & .006 & .122 & .037 & .379 \\
Q10 & -.127 & .398 & .047 & .467 & .100 \\
Q11 & .169 & .179 & .555 & -.155 & .287 \\
Q12 & .053 & -.082 & -.612 & .228 & .416 \\
Q13 & .022 & .020 & .083 & .017 & -.790 \\
Q14 & .003 & -.058 & .720 & .210 & -.091 \\
Q15 & -.154 & -.192 & -.119 & .610 & .073 \\
Q16 & .703 & .119 & .030 & -.027 & -.021 \\
Q17 & .751 & .106 & .063 & .041 & -.032 \\
Q18 & .294 & .579 & .103 & .082 & .232 \\
Q19 & .536 & .240 & -.104 & -.016 & -.038 \\
Q20 & .139 & .151 & .201 & .594 & -.011 \\
Q21 & .137 & .661 & -.078 & -.142 & -.167 \\
Q22 & .162 & .748 & .118 & .090 & -.025 \\
Q23 & .244 & -.039 & -.335 & .531 & -.237 \\
\hline
\end{tabular}




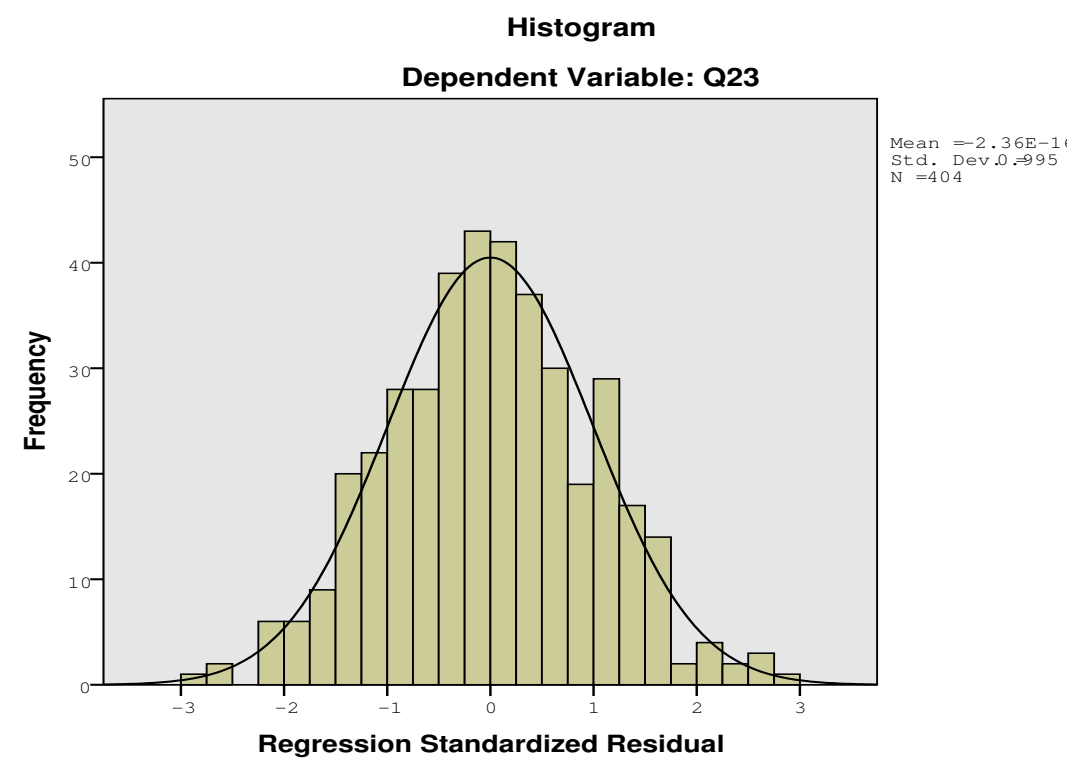

Figure 3. Regression Residual Distribution

Table 7. Regression Coefficients

\begin{tabular}{lccccccc}
\hline Model & \multicolumn{2}{c}{$\begin{array}{c}\text { Unstandardized Coefficients } \\
\text { B }\end{array}$} & $\begin{array}{c}\text { Standardized Coefficients } \\
\text { Std. Error }\end{array}$ & $\mathrm{t}$ & Sig. & \multicolumn{2}{c}{ Collinearity Statistics } \\
Beta & & & Tolerance & VIF \\
\hline (Constant) & 2.364 & .030 & & 77.536 & .000 & & \\
factor 1 & .212 & .031 & .244 & 6.958 & .000 & 1.000 & 1.000 \\
factor 3 & -.291 & .031 & -.335 & -9.549 & .000 & 1.000 & 1.000 \\
factor 4 & .462 & .031 & .531 & 15.147 & .000 & 1.000 & 1.000 \\
factor 5 & -.206 & .031 & -.237 & -6.752 & .000 & 1.000 & 1.000 \\
\hline
\end{tabular}

The regression performed by SPSS. Thus the results showed by Table 7 and explained by the equation: Preferences for EVs $=2.364+0.212 \times$ Awareness of environment $-0.291 \times$ EVs operation cost $+0.462 \times$ Private car demand $+0.061 \times$ travel mileage of consumer.

\subsection{Consumers Purchasing Willingness and Attitude}

About purchasing willingness to EVs, the study examined the first-time car buyers response. The Figure 4 showed that $41.7 \%(n=170)$ respondents wished to buy EVs considering recharging station convenient, $36 \%(n=147)$ participants expressed strong interests in EVs because of advantages. Besides, it examined the buyers' willingness to EVs at the second time, which revealed that $54.9 \%$ $(n=224)$ members had more willingness than before, 31.6\% $(n=129)$ respondents had the desire to buy EVs as the second car. Thus, there was $8.8 \%(n=129)$ members' willingness increment comparing to the first-time. However, further analysis showed significant differences between occupation ( $\mathrm{p}$-value $=0.025)$, income level $(\mathrm{p}$-value $=0.021)$ and buying desire. It revealed that office worker had more desire to buy EVs than others, middle-income level respondents showed same desire as well. While one respondent had a private car and driving experiences, he or she had greater chance to buy EVs than others. 


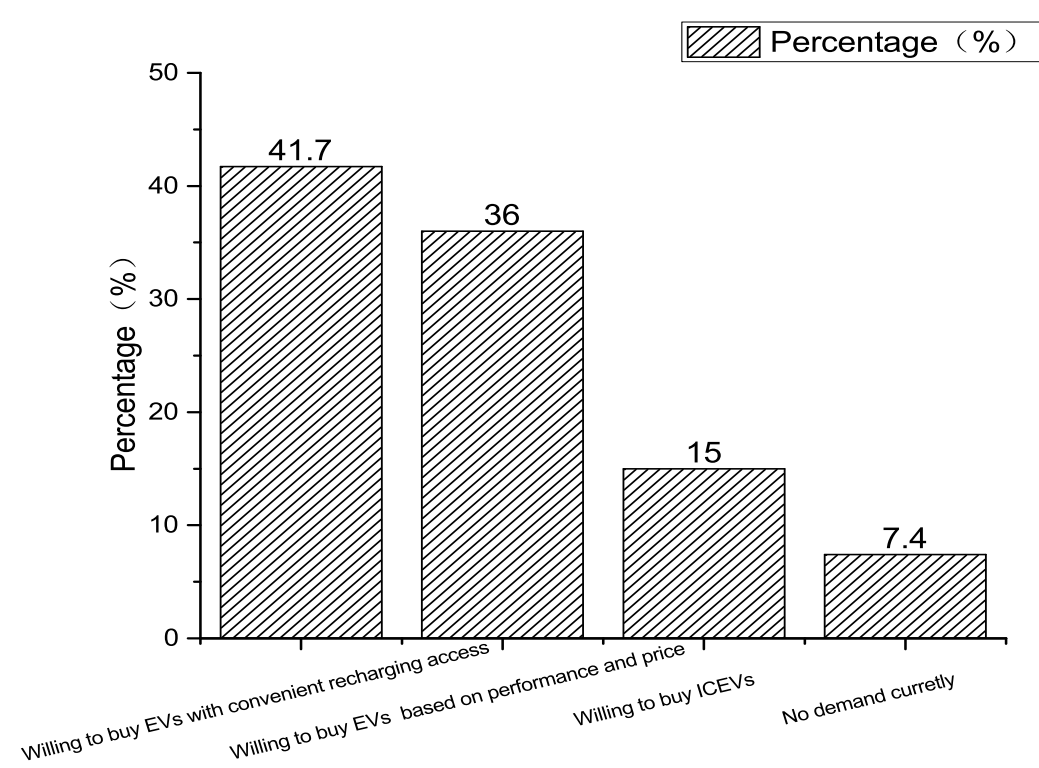

Figure 4. Willingness of The First time Car Buyer

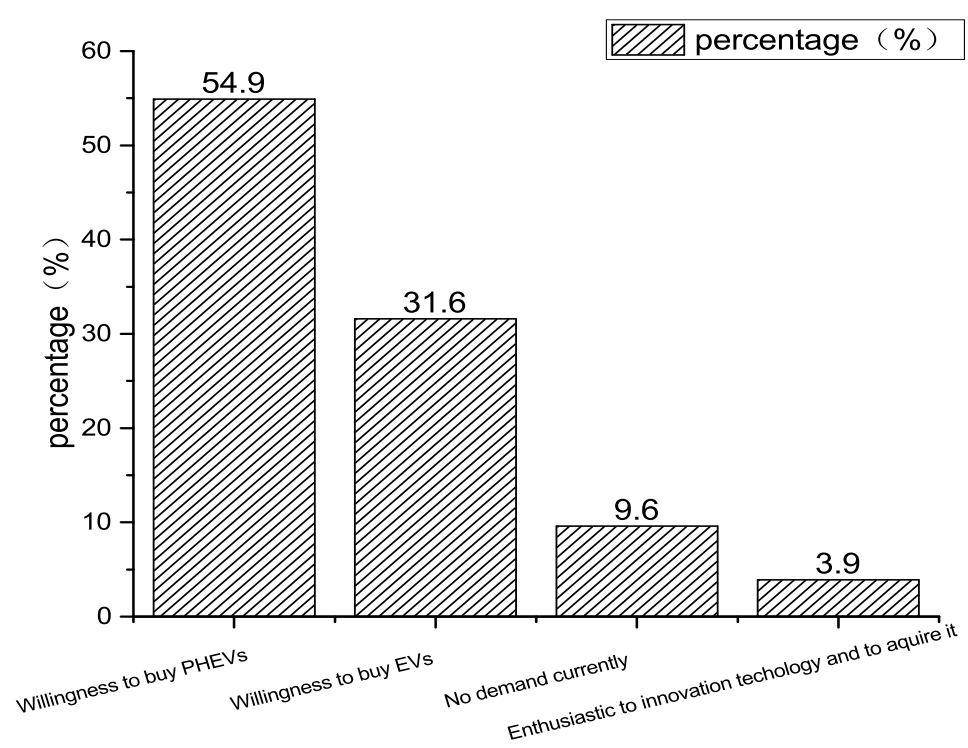

Figure 5. Willingness of The Second time Car Buyer 


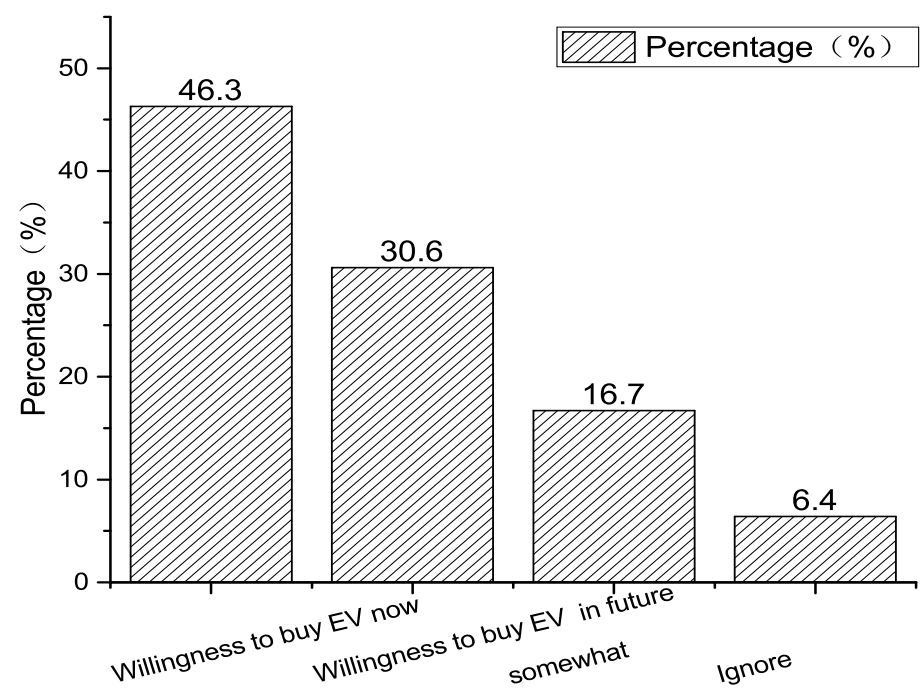

Figure 6. Willingness to buy EVs considering national energy safety

Also, the research inferred that social circle, public policy, and energy security concern influenced the consumers' willingness, and which showed by Figure 6 and Table 8. The analysis revealed that $29.9 \%(n=122)$ members' desire changed based on friend's opinion, $27.9 \%$ respondents' willingness alternated because of family member's opinion. Further, considering energy security concern, $46.3 \%(n=189)$ members expressed the strong desire to buy EVs now, 30.6\%( $n=125)$ members had the desire to buy EVs in future, $16.7 \%(n=68)$ members expressed somewhat want to buy EVs. Overall, the total percentage of consumers' willingness increased to $93.6 \%(n=382)$.

Table 8. Association Test for Willingness to Buy EVs

\begin{tabular}{ccc}
\hline Factors & Pearson Chi-Square Sig. & Fisher's Exact Test Sig. \\
\hline Occupation & 0.043 & 0.025 \\
Income level & 0.014 & 0.025 \\
Society network members & 0 & 0.001 \\
ICVs technology improve & 0 & 0 \\
Attitude toward Evs & 0.001 & 0.001 \\
\hline
\end{tabular}

By fuel saving technology grow, or fossil fuel price drop significantly in future, the respondents still had the strong desire to buy EVs. The percentage occupied $75.8 \%$ and $80.7 \%$ respectively, and presented in Figure 8. When the fuel price rises, the intent to buy EVs will increase more significantly. 


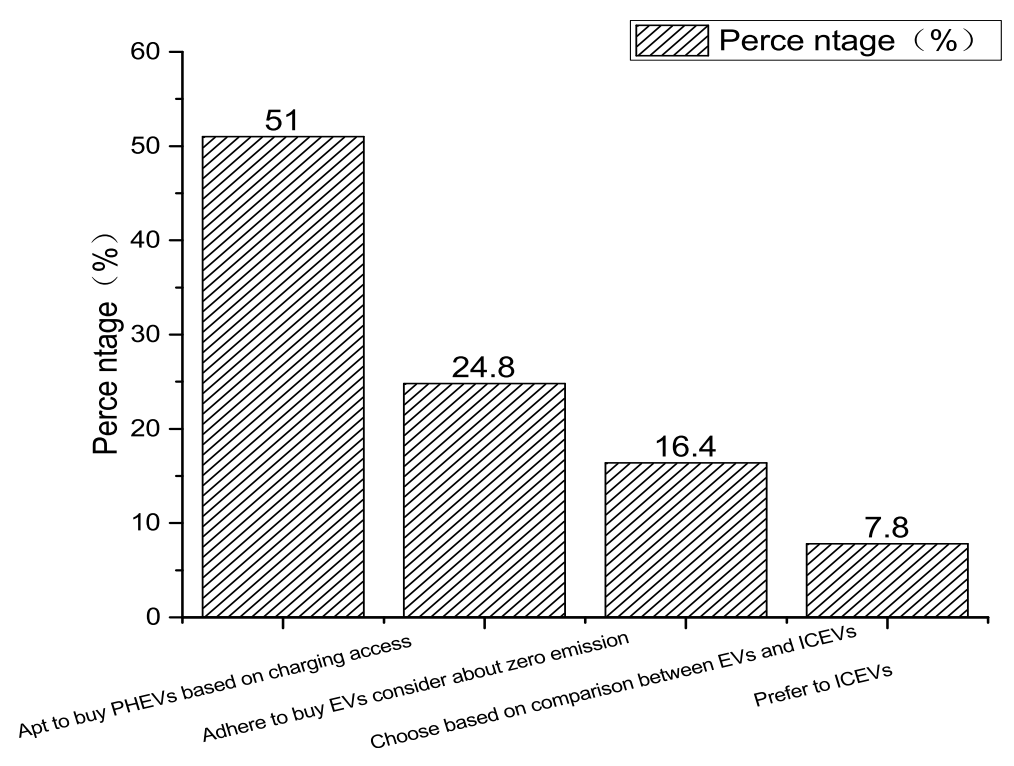

Figure 7. Purchasing Willingness Based on ICEVs Technology Improvement

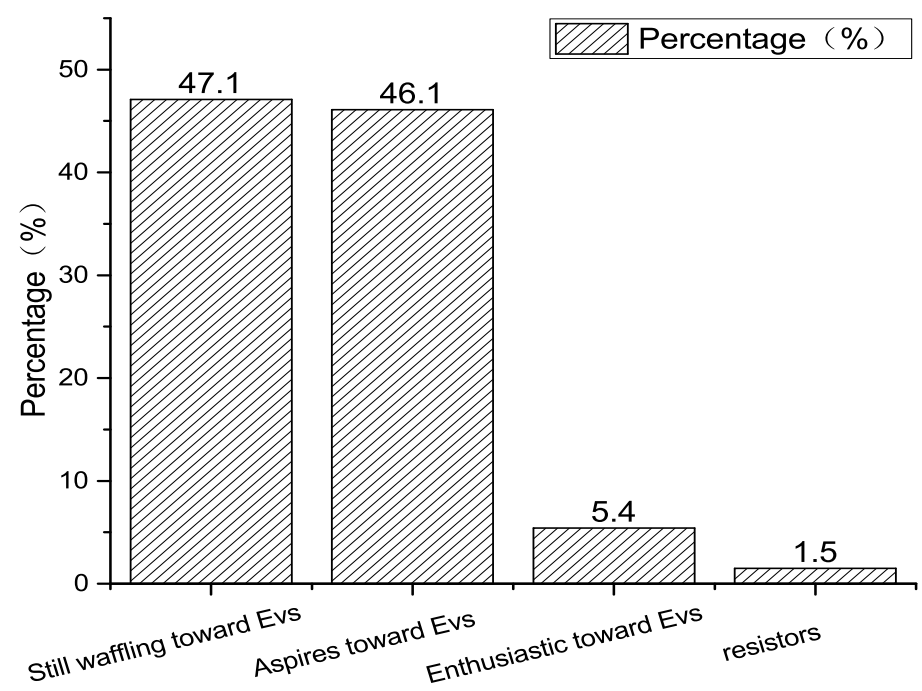

Figure 8. The Participants attitudes toward EVs

Many experts suggested that EVs would be a good choice for environment conservation and energy security. However, consumers' attitudes were critical to EVs large-scale penetration. The study inferred by Figure 9 that $47.1 \%(\mathrm{n}=192)$ members kept undecided toward EVs, and $46.1 \%(\mathrm{n}=188)$ members showed aspires toward EVs. Besides, $5.4 \%(\mathrm{n}=22)$ members were enthusiastic to EVs, and Only $1.5 \%$ respondents were against EVs. Besides, Fisher tests showed significant differences between participants attitudes and willingness as showed in Table 8 ( $p=$ value $=0.001$ ), which means the more positive attitudes toward EVs, the stronger desire to buy EVs.

On the insights of large-scale penetration, the study showed that most of the members (46.8\%) held positive opinion toward EVs by Figure 9. Moreover, 38.2\% members believed that EVs would be mainstream in future. 


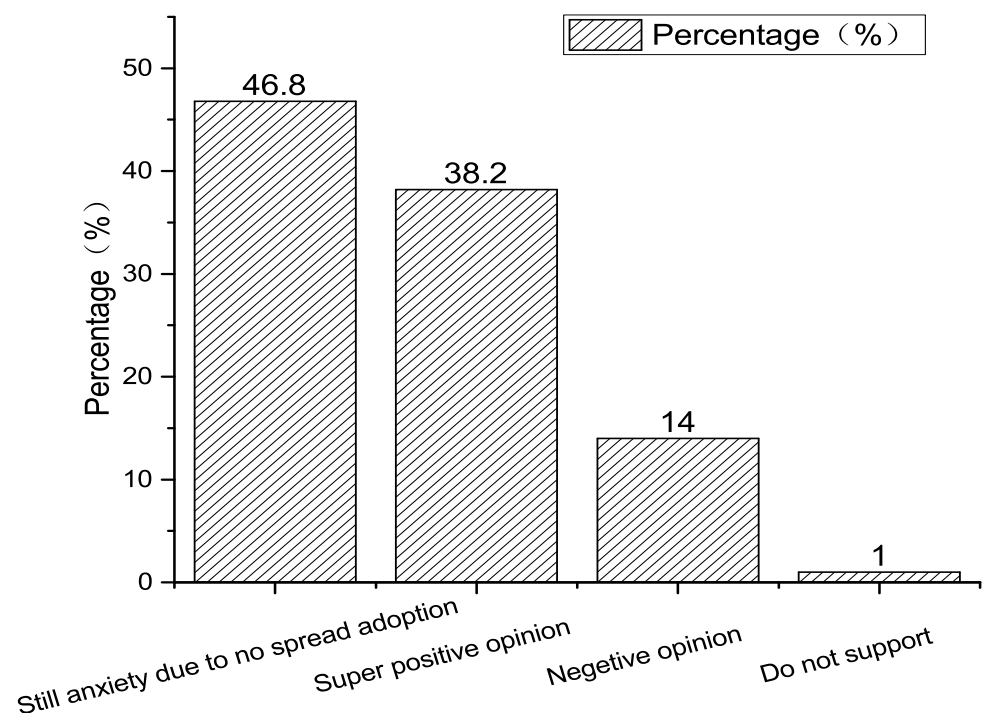

Figure 9. The Participants insights of spread adoption of EVs in future

Besides, the study conducted the factor analyze to explore the main elements in this section by SPSS. The results showed by Table 9, Table 10 and Table 11:

Table 9. KMO and Bartlett's Test

\begin{tabular}{llr}
\hline Kaiser-Meyer-Olkin Measure of Sampling Adequacy. & .771 \\
& Approx. Chi-Square & 1420.388 \\
Bartlett's Test of Sphericity & df & 153 \\
& Sig. & .000 \\
\hline
\end{tabular}

Table 10. Total Variance Explained

\begin{tabular}{|c|c|c|c|c|c|c|c|c|c|}
\hline \multirow[b]{2}{*}{ Component } & \multicolumn{3}{|c|}{ Initial Eigenvalues } & \multicolumn{3}{|c|}{ Extraction Sums of Squared Loadings } & \multicolumn{3}{|c|}{ Rotation Sums of Squared Loadings } \\
\hline & Total & $\%$ of Variance & Cumulative \% & Total & $\%$ of Variance & Cumulative $\%$ & Total & $\%$ of Variance & Cumulative \% \\
\hline 1 & 3.834 & 21.297 & 21.297 & 3.834 & 21.297 & 21.297 & 2.603 & 14.463 & 14.463 \\
\hline 2 & 1.863 & 10.348 & 31.645 & 1.863 & 10.348 & 31.645 & 2.054 & 11.410 & 25.873 \\
\hline 3 & 1.498 & 8.323 & 39.968 & 1.498 & 8.323 & 39.968 & 1.813 & 10.071 & 35.944 \\
\hline 4 & 1.089 & 6.048 & 46.016 & 1.089 & 6.048 & 46.016 & 1.543 & 8.575 & 44.519 \\
\hline 5 & 1.035 & 5.749 & 51.765 & 1.035 & 5.749 & 51.765 & 1.304 & 7.246 & 51.765 \\
\hline 6 & .999 & 5.550 & 57.315 & & & & & & \\
\hline 7 & .948 & 5.269 & 62.585 & & & & & & \\
\hline 8 & .851 & 4.728 & 67.312 & & & & & & \\
\hline 9 & .810 & 4.502 & 71.814 & & & & & & \\
\hline 10 & .742 & 4.122 & 75.937 & & & & & & \\
\hline 11 & .691 & 3.839 & 79.776 & & & & & & \\
\hline 12 & .660 & 3.668 & 83.444 & & & & & & \\
\hline 13 & .647 & 3.596 & 87.040 & & & & & & \\
\hline 14 & .588 & 3.268 & 90.308 & & & & & & \\
\hline 15 & .549 & 3.052 & 93.360 & & & & & & \\
\hline 16 & .530 & 2.943 & 96.303 & & & & & & \\
\hline 17 & .449 & 2.492 & 98.795 & & & & & & \\
\hline 18 & .217 & 1.205 & 100.000 & & & & & & \\
\hline
\end{tabular}


Table 11. Rotated Component Matrixa

\begin{tabular}{lccccc}
\hline \multicolumn{5}{c}{ Component } \\
\hline & 1 & 2 & 3 & 4 & 5 \\
Q24 & .628 & & & & \\
Q25 & & & .935 & & \\
Q26 & & & .926 & & \\
Q27 & & & & & \\
Q28 & & & & & \\
Q29 & & & & & \\
Q30 & & & & & \\
Q31 & .554 & & & & \\
Q32 & .526 & & & & \\
Q33 & & .532 & & & \\
Q34 & & .678 & & & \\
Q35 & & .636 & & & \\
Q36 & & & & & \\
Q37 & .603 & & & & \\
Q38 & & & & .815 & \\
Q39 & & & & & \\
Q40 & & & & \\
Q41 & .680 & & & \\
\hline
\end{tabular}

KMO (Kaiser-Meyer-Olkin) test of factor analysis carried out by SPSS and presented in Table 9, while the KMO value greater than 0.5 , which implied the original data was suitable for factor analysis. The total variances of all components explained by the table 10 . The study extracted the common elements and divided into five groups by SPSS in Table 11:

I.Perception of EVs : Feeling or sense about EVs based on experiences and knowledge

II.EVs competitiveness: EVs exceptional performance comparing with ICEVs or other fuel vehicles III.EVs prices: EVs market price.

IV.EVs full-charge range: Duration mileage of EVs with fully battery charge.

V.EVs operation cost: Operation cost within life cycle period.

Besides, the study carried regression by SPSS based on the common factors. The results showed by Figure 10, Figure 11, Table 12 and Table 13.

Thus, The attitude toward $\mathrm{EVs}=2.446+0.390 \times$ Perception of $\mathrm{EVs}+0.127 \times \mathrm{EVs}$ competitiveness $+0.073 \times$ EVs full-charge range.

Further, Buying willingness of $\mathrm{EVs}=1.944+0.259 \times$ Perception of EVs $+0.670 \times$ EVs competitiveness $+0.182 \times$ EVs prices $-0.182 \times$ EVs operation cost. 


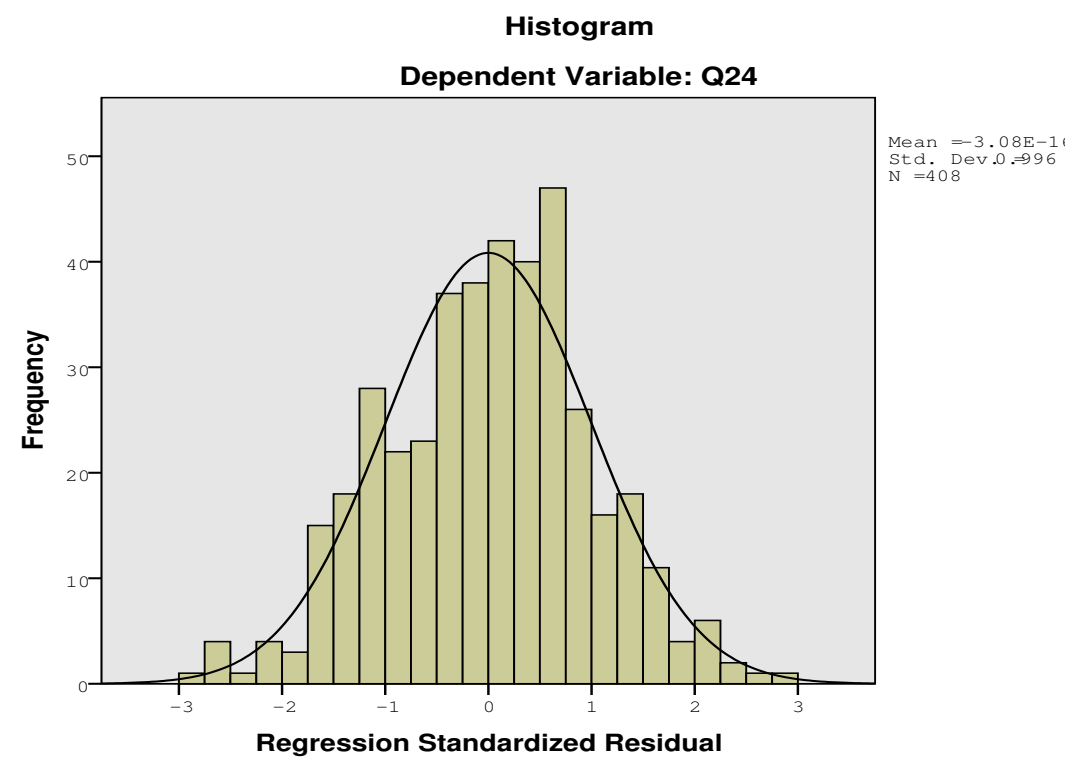

Figure 10. The regression standard residual of attitude toward EVs

Table 12. Regression Coefficients

\begin{tabular}{|c|c|c|c|c|c|c|c|}
\hline \multirow{2}{*}{ Model } & \multicolumn{2}{|c|}{ Unstandardized Coefficients } & \multirow{2}{*}{$\begin{array}{c}\text { Standardized Coefficients } \\
\text { Beta }\end{array}$} & \multirow{2}{*}{$\mathrm{t}$} & \multirow{2}{*}{ Sig. } & \multicolumn{2}{|c|}{ Collinearity Statistics } \\
\hline & B & Std. Error & & & & Tolerance & VIF \\
\hline (Constant) & 2.446 & .023 & & 106.930 & .000 & & \\
\hline factor score 1 & .390 & .023 & .628 & 17.011 & .000 & 1.000 & 1.000 \\
\hline factor score 2 & .127 & .023 & .205 & 5.558 & .000 & 1.000 & 1.000 \\
\hline factor score 4 & .073 & .023 & .118 & 3.197 & .001 & 1.000 & 1.000 \\
\hline
\end{tabular}

Dependent Variable: Attitudes toward EVs

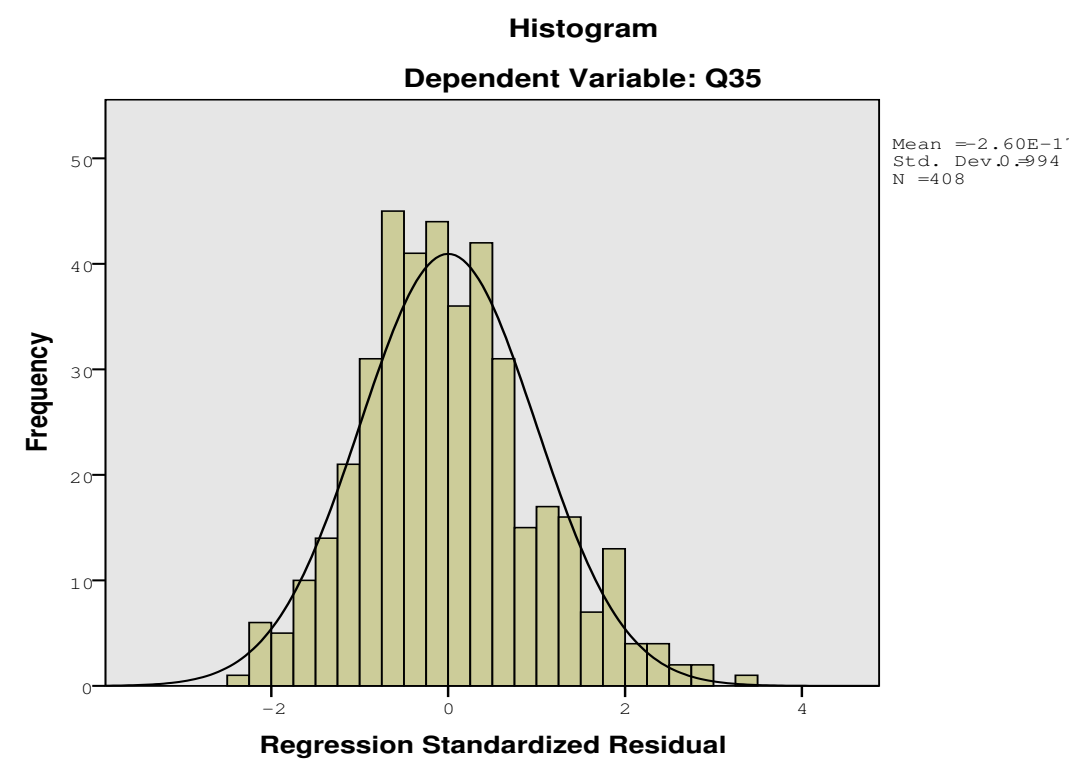

Figure 11. The regression standard residual of purchasing willingness to EVs 
Table 13. Regression Coefficients

\begin{tabular}{cccccccc}
\hline \multirow{2}{*}{ Model } & \multicolumn{2}{c}{$\begin{array}{c}\text { Unstandardized Coefficients } \\
\text { B }\end{array}$} & $\begin{array}{c}\text { Standardized Coefficients } \\
\text { Std. Error }\end{array}$ & Beta & & \multirow{2}{*}{ Sig. } & \multicolumn{2}{c}{ Collinearity Statistics } \\
& Tolerance & VIF \\
\hline (Constant) & 1.944 & .036 & & 53.732 & .000 & & \\
factor 1 & .259 & .036 & .245 & 7.140 & .000 & 1.000 & 1.000 \\
factor 2 & .670 & .036 & .636 & 18.487 & .000 & 1.000 & 1.000 \\
factor 3 & .182 & .036 & .172 & 5.016 & .000 & 1.000 & 1.000 \\
factor 5 & -.182 & .036 & -.173 & -5.023 & .000 & 1.000 & 1.000 \\
\hline
\end{tabular}

a. Dependent Variable: Purchasing willingness

\subsection{Public Policy and Price Incentive}

Trying to encourage consumers spread adopt EVs, the government settled series of public policy and financial subsidies to stimulate EVs large-scale penetration. China government-supported grant presented in Table 14 and Table 15. This study made a comparison about buying willingness to EVs between financial subsidies support at current and drop in future by Figure 12, Figure 13 and Figure 14 . The study showed that $65.7 \%$ of members had the desire to buy EVs based on financial subsidies, and $63.9 \%$ members had the desire to buy PHEVs based on the grant as well. Besides, if the government cancel or reduce the subsidies by 2020, the buying desire would drop but not significantly. It showed by Figure 14 there were $45.6 \%$ respondents still consider buying EVs because of technology trend and market share expectation. Also, 22.3\% members insisted on buying EVs based on their attitudes toward EVs. Further, comparing with consumers' willingness status, a Chinese government published data showed that EVs yield (Figure 15) increased robustly in the past three years.

Table 14. EVs price subsides in China

\begin{tabular}{ccccc}
\hline \multirow{2}{*}{ Vehicle Type } & \multicolumn{3}{c}{ Range with Pure Electricity Model } \\
& $80 \mathrm{Km} \leqslant \mathrm{R} \leq 150 \mathrm{Km}$ & $150 \mathrm{Km} \leqslant \mathrm{R} \leqslant 250 \mathrm{Km}$ & $\mathrm{R} \geq 250 \mathrm{Km}$ & $\mathrm{R} \geq 50 \mathrm{Km}$ \\
\hline PEVs(2013) Unit: Ones & $\$ 5,319.07$ & $\$ 7,598.67$ & $\$ 9,118.40$ & $\mathrm{~N}$ \\
PEVs(2014) Unit: Ones & $\$ 5,319.07$ & $\$ 7,598.67$ & $\$ 9,118.40$ & $\mathrm{~N}$ \\
PHEVs(2013) Unit:Ones & & & & $\$ 5,319.07$ \\
PHEVs(2014) Unit:Ones & & & $\$ 5,319.07$ \\
\hline
\end{tabular}

Table 15. EVs price subsides in Shenzhen

\begin{tabular}{ccccc}
\hline \multirow{2}{*}{ Vehicle Type } & \multicolumn{3}{c}{ Range with Pure Electricity Model } \\
& $80 \mathrm{Km} \leqslant \mathrm{R} \leq 150 \mathrm{Km}$ & $150 \mathrm{Km} \leqslant \mathrm{R} \leqslant 250 \mathrm{Km}$ & $\mathrm{R} \geq 250 \mathrm{Km}$ & $\mathrm{R} \geq 50 \mathrm{Km}$ \\
\hline PEVs(2013) Unit: Ones & $\$ 5,319.07$ & $\$ 7,598.67$ & $\$ 9,118.40$ & $\mathrm{~N}$ \\
PEVs(2014) Unit: Ones & $\$ 5,319.07$ & $\$ 7,598.67$ & $\$ 9,118.40$ & $\mathrm{~N}$ \\
PHEVs(2013) Unit:Ones & & & & $\$ 5,319.07$ \\
PHEVs(2014) Unit:Ones & & & $\$ 5,319.07$ \\
\hline
\end{tabular}




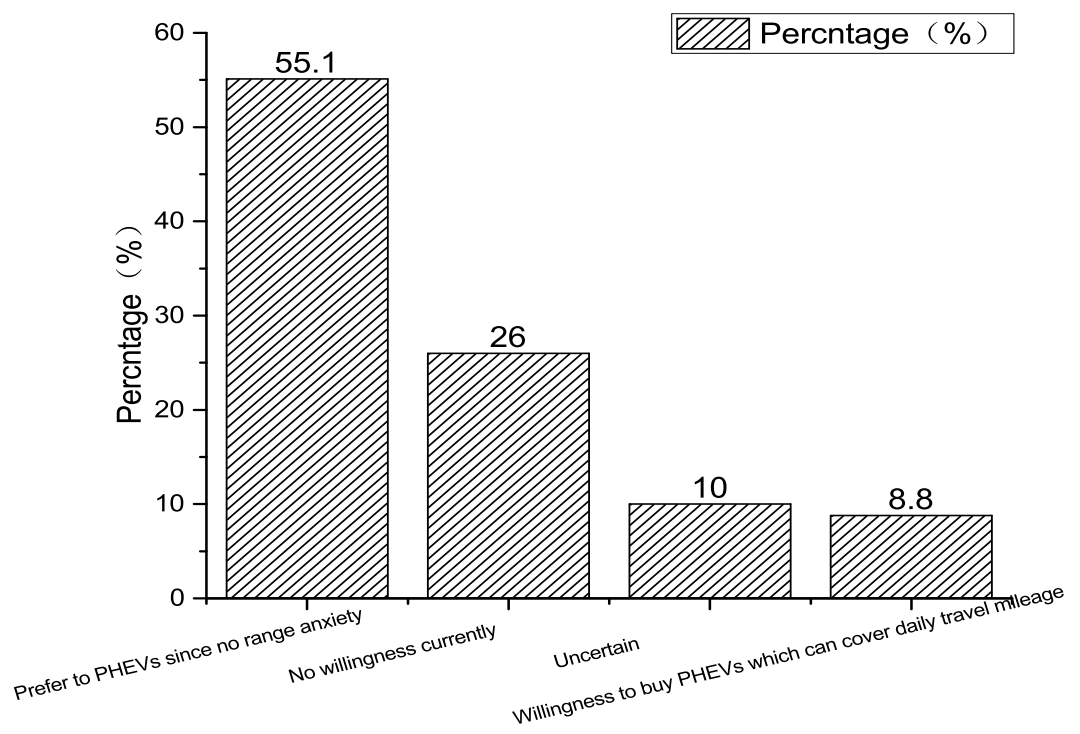

Figure 12. PHEVs purchasing Willingness Based on Incentives

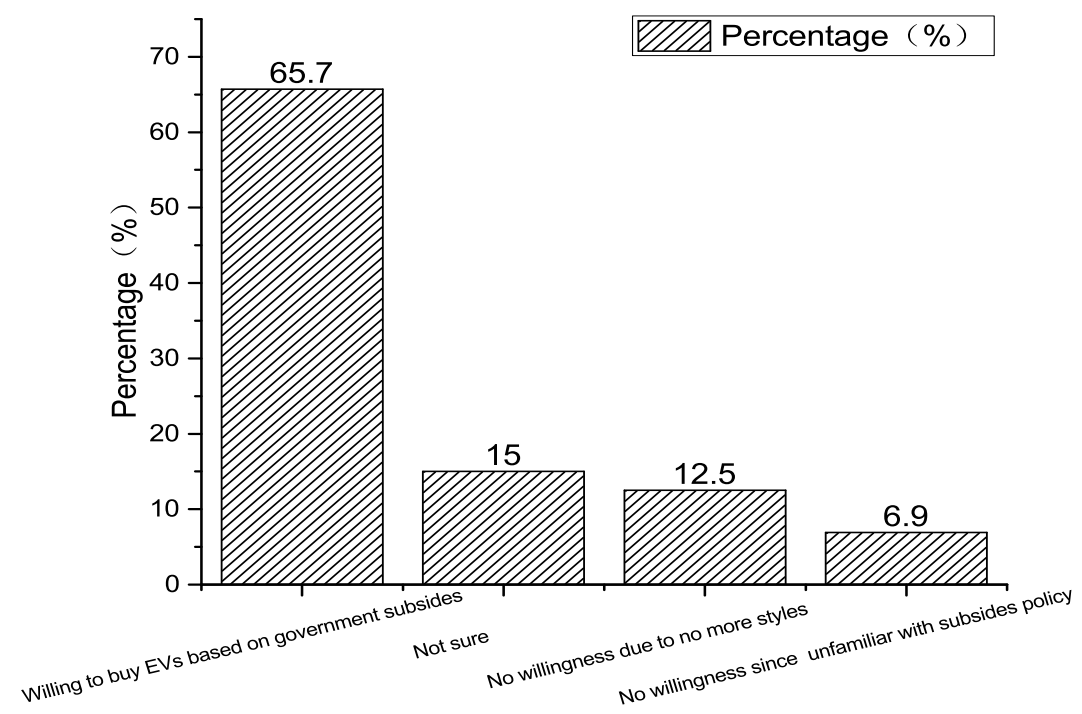

Figure 13. EVs Purchasing Willingness Based on Inventives 


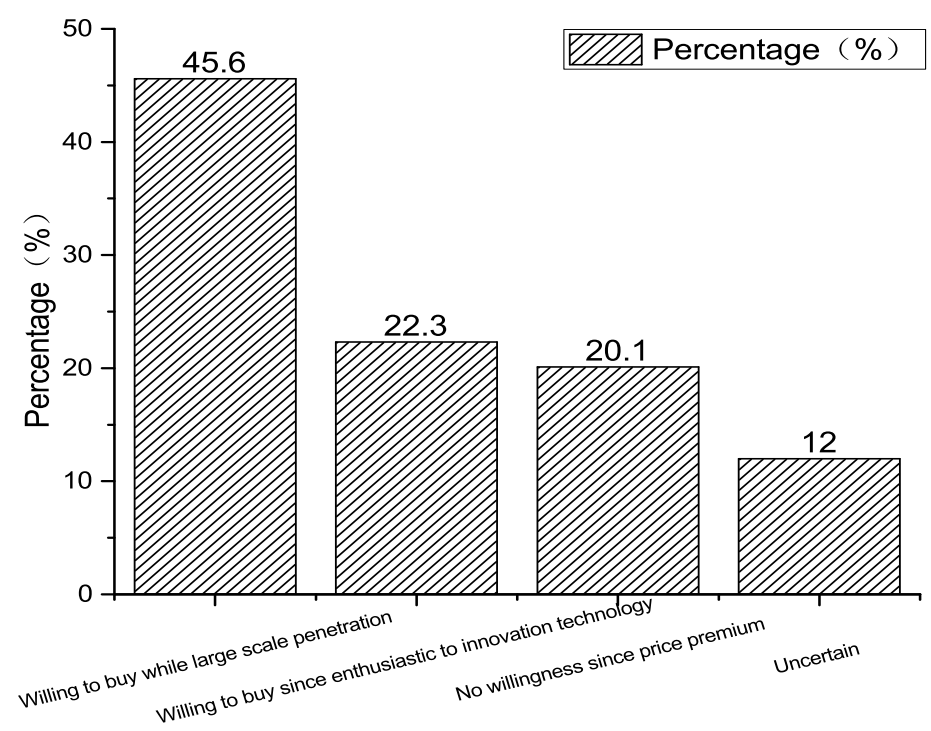

Figure 14. Willingness Changed When Subsides Canceled by 2020

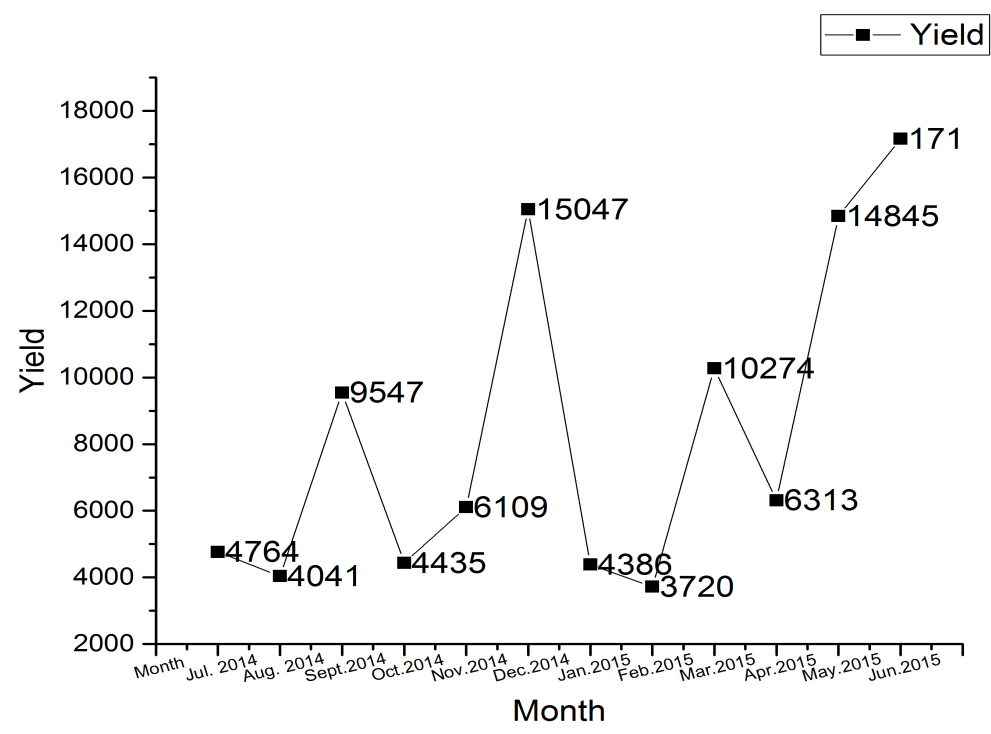

Figure 15. Passengers EVs Yield Past Years

About EVs price premium, this study examined the Shenzhen residents' acceptance degree of EVs price. The results showed that $50 \%(n=204)$ of respondents' expectation range concentrated between $\$ 13071$ and $\$ 24509$. Also, 37.3\% ( $n=152)$ of respondents price expectation range concentrated between $\$ 24509$ to $\$ 40849$. Besides, $10.3 \%$ ( $n=42$ ) of participants price expectation range concentrated between $\$ 40849$ to $\$ 65359$ and only $2.5 \%$ percent respondents could accept EVs price range upper \$65359. With consumers acceptance of PHEVs prices, which had similarly statistical result with EVs. As it examined the EVs sales price in China market which showed the main products price range concentrated between $\$ 24509$ and $\$ 40849$.

Further, the study carried the factors analysis and regression by SPSS. The KMO test inferred the data was suitable for the factor analysis, the results presented in Table 16, Table 17, Table 18 and 
Table 19:

Table 16. KMO and Bartlett's Test

\begin{tabular}{llr}
\hline Kaiser-Meyer-Olkin Measure of Sampling Adequacy. & .818 \\
& Approx. Chi-Square & 839.176 \\
Bartlett's Test of Sphericity & df & 66 \\
& Sig. & .000 \\
\hline
\end{tabular}

Table 17. Total Variance Explained

\begin{tabular}{|c|c|c|c|c|c|c|c|c|c|}
\hline \multirow[b]{2}{*}{ Component } & \multicolumn{3}{|c|}{ Initial Eigenvalues } & \multicolumn{3}{|c|}{ Extraction Sums of Squared Loadings } & \multicolumn{3}{|c|}{ Rotation Sums of Squared Loadings } \\
\hline & Total & $\%$ of Variance & Cumulative \% & Total & $\%$ of Variance & Cumulative \% & Total & $\%$ of Variance & Cumulative \% \\
\hline 1 & 3.321 & 27.672 & 27.672 & 3.321 & 27.672 & 27.672 & 2.767 & 23.059 & 23.059 \\
\hline 2 & 1.402 & 11.687 & 39.359 & 1.402 & 11.687 & 39.359 & 1.915 & 15.961 & 39.020 \\
\hline 3 & 1.094 & 9.117 & 48.476 & 1.094 & 9.117 & 48.476 & 1.135 & 9.456 & 48.476 \\
\hline 4 & .959 & 7.988 & 56.464 & & & & & & \\
\hline 5 & .921 & 7.672 & 64.136 & & & & & & \\
\hline 6 & .775 & 6.459 & 70.595 & & & & & & \\
\hline 7 & .758 & 6.315 & 76.910 & & & & & & \\
\hline 8 & .673 & 5.606 & 82.516 & & & & & & \\
\hline 9 & .646 & 5.385 & 87.901 & & & & & & \\
\hline 10 & .597 & 4.974 & 92.875 & & & & & & \\
\hline 11 & .468 & 3.900 & 96.775 & & & & & & \\
\hline 12 & .387 & 3.225 & 100.000 & & & & & & \\
\hline
\end{tabular}

Extraction Method: Principal Component Analysis.

Table 18. Rotated Component Matrix

\begin{tabular}{cccc}
\hline \multicolumn{4}{c}{ Component } \\
\hline & 1 & 2 & 3 \\
Q42 & & & .566 \\
Q43 & & .643 & \\
Q44 & & & .663 \\
Q45 & .726 & & \\
Q46 & & & .550 \\
Q47 & .742 & & \\
Q48 & .733 & & \\
Q49 & .660 & & \\
Q50 & .677 & & \\
Q51 & & .545 & \\
Q52 & \multicolumn{3}{c}{.620} \\
Q53 & \multicolumn{4}{c}{.757} \\
\hline
\end{tabular}

Table 19. Regression Coefficients

\begin{tabular}{|c|c|c|c|c|c|c|c|}
\hline \multirow{2}{*}{ Model } & \multicolumn{2}{|c|}{ Unstandardized Coefficients } & \multirow{2}{*}{$\begin{array}{c}\text { Standardized Coefficients } \\
\text { Beta }\end{array}$} & \multirow[b]{2}{*}{$\mathrm{t}$} & \multirow{2}{*}{ Sig. } & \multicolumn{2}{|c|}{ Collinearity Statistics } \\
\hline & B & Std. Error & & & & Tolerance & VIF \\
\hline (Constant) & 1.429 & .029 & & 48.634 & .000 & & \\
\hline factor score 1 & .225 & .029 & .296 & 7.634 & .000 & 1.000 & 1.000 \\
\hline factor score 3 & .417 & .029 & .550 & 14.174 & .000 & 1.000 & 1.000 \\
\hline
\end{tabular}

a. Dependent Variable: Purchasing willingness 
The study extracted the Rotated components by SPSS and presented the common factors as below:

\section{I.Price subsidies}

II.Public Policy Support:Public policy supporting EVs operation conveniently.

III.EVs Charge infrastructure placement: Recharge station placement for EVs spread adoption.

Besides, the paper examined the relationship between common factors and the dependent variable by regression analysis. It inferred the regression equation like this:Buying willingness $=1.429+0.025 \times$ public policy support $+0.417 \times$ EVs charge infrastructure deployment.

\section{Discussion}

\subsection{Preference for $E V s$}

This study shows the results limited to support the hypotheses \#1 by basic statistical analysis and Fisher test. However, the regression infers that consumer's real demand of private car fixes the preference for EVs[6]. Thus, it needs more research on potential users to evaluate their behaviors for EVs spread adoption[11]. Also, the results show the awareness of environmental and national energy security has a significant influence on consumer's preference[10,11,14,15,17]. It verifies the public policy driven and environmental knowledge education from the central and local government of China. Consistence with previous findings, an inverse proportional to the preference in regression analysis indicates that consumers also aim for lower using cost with EVs[11,21,26].

\subsection{Consumers Purchasing Willingness and Attitude}

Overall, the basic statistical analysis shows the participants have strong willingness to adopt EVs no matter first-time car buyer or non-fist time. They hold on optimistic about the prospective of EVs spread adoption[11,31]. However, most of them concern about convenient recharging access. Although Chinese consumers express a strong will to buy EVs, to gain the main items influencing on consumers buying decision, it needs quantitative analysis. The study conducts the regression, which shows the perceptions, advantages and full-charge range of EVs fix consumers' attitudes toward EVs $[7,19,20,23]$. It support the hypotheses\#2 and hypotheses \#3. Besides, the perception item has maximum regression coefficient which means it influences the consumers' attitudes significantly[7,10].

Also, the regression reveals the factors determined consumers' buying willingness, which including perceptions, technology advantages[20,21], price and the cost of driving EVs [4,20,21]. Besides, the cost of driving EVs has an reversed relationship to the buying willingness. All other coefficients are positive, and EVs advantages account for a higher percentage. It infers that when customers have enough opportunity to experience EVs, consumer's perceptions of EVs will rise significantly, and buying willingness rise simultaneously[23,24]. Further, considering EVs performance, if EVs advantages better than ICEVs, which also increase the consumers desires significantly. As explained by regression analysis that EVs price is not primary factor influence on buying willingness. The result show differences with previous findings that price premium is critical barrier to EVs adoption[6,8,10].

\subsection{Public Policy and Price Incentive}

The study implies the public policy on EVs affects the consumers buying willingness, such as central government price subsidies and local government subsidies. Factor analysis indicates that state strategic support and charging point placement are crucial elements to EVs spread adoption[9,25,26,35]. It supports the hypotheses 3 and 4 . However, the result rejects the assumption 5 and hold new point that subsidies drop in future will not influence the participants buying willingness significantly.

This paper inherits the general structure of the formal research, which results verify many 
conclusions of the previous studies. Also, it replenishes the earlier studies' limit findings that survey respondents have no driving experiences of EVs[1,41]. The study's contribution is that most surveyed participants who have direct experiences in driving EVs, thus the situation of participants can reflect the real status of consumers behaviors accurately. Besides, the study proposes five types of hypotheses based on formal research findings and then verifies the assumptions by statistical analysis. Moreover, it is valuable for carmaker or government to identify the potential market trend and adjust the EVs industrial policies in China.

\section{Conclusions}

First, the study inferred that participants had high willingness to buy EVs, which limited support the hypothesis. However, considering EVs spread adoption, the uptake of EVs depends on more recharging access placement in community and working place rather than the public recharging station $[11,27,28,40]$. Second, the research showed that perception of EVs could be a significant barrier to EVs penetration[23,41]. Only consumers can get the EVs knowledge accurately and experience it regularly, the attitudes and willingness toward EVs will rising significantly. Besides, it revealed that EVs maker or government should do more promotion related to EVs technology advantages. Also, about recharging behavior, it suggested that majority of consumers prefer to home night charging and working place charging. Besides, the study revealed that EVs competitiveness, full-charge range, EVs price, operation cost and public policy were crucial factors to widespread of EVs, which supports the hypotheses well. However, it hold new point that financial incentives drop and EVs price premium were not barriers to EVs spread adoption, which verified by the analysis and limited supported the hypotheses.

There were several drawbacks existed in current research. First, the survey population was limit so the results may not be representative the overall status well. Second, future study should improve the survey questionnaire and ensure it is suitable for statistical analysis. Besides, the gender proportion should more balance than currently.

The study is valuable for EVs makers understanding about Chinese consumption behaviors. However, it was only a research focusing on region status at current. The future research is aim to do more comparison study between Shenzhen and some other China cities about EVs adoption. Besides, it is valuable to do more research across the cultural differences in global scope.

\section{Acknowledgments}

The authors gratefully acknowledge the work of China BYD company and their colleagues at EVs retailer management division for check the questionnaire used for the survey. We would also like to express our gratitude to the researchers in our lab who provide raw data check and review in the study.

In addition, this work is supported by the National Natural Science Foundation of China (Grant No. 71202022), the National Natural Science Foundation of China (Grant No. 71572090), the Natural Science Foundation of Guang Dong Province(Grant No.2015A030313824), the Natural Science Foundation of Guang Dong Province(Grant No.2014A030310404) and Shenzhen city Special Strategic Emerging Industry Development (Grant No.JCYJ20150331151358130)

\section{Appendix}

The questionnaire mentioned in our study is available in the URL of"http://www.lediaocha.com/ pc/s/neutew "

\section{Reference}

1. Rezvani, Z., J. Jansson, and J. Bodin, Advances in consumer electric vehicle adoption research: A review and research agenda. Transportation Research Part D: Transport and Environment, 2015. 34: p. 122-136. 
2. Krupa, J.S., et al., Analysis of a consumer survey on plug-in hybrid electric vehicles. Transportation Research Part A: Policy and Practice, 2014. 64: p. 14-31.

3. Axsen, J. and K.S. Kurani, <Axsen, J., Kurani, K.S., 2008. The Early U.S. Market for PHEVs Anticipating Consumer Awareness, Recharge Potential, Design Priorities and Energy Impacts.pdf $>$. 2008.

4. Larson, P.D., et al., Consumer attitudes about electric cars: Pricing analysis and policy implications. Transportation Research Part A: Policy and Practice, 2014. 69: p. 299-314.

5. Carley, S., et al., Intent to purchase a plug-in electric vehicle: A survey of early impressions in large US cites. Transportation Research Part D: Transport and Environment, 2013. 18: p. 39-45.

6. Axsen, J., J. Bailey, and M.A. Castro, Preference and lifestyle heterogeneity among potential plug-in electric vehicle buyers. Energy Economics, 2015. 50: p. 190-201.

7. Egbue, O. and S. Long, Barriers to widespread adoption of electric vehicles: An analysis of consumer attitudes and perceptions. Energy Policy, 2012. 48: p. 717-729.

8. Wang, X., Z. Yang, and N.R. Liu, The Impacts of Brand Personality and Congruity on Purchase Intention: Evidence From the Chinese Mainland's Automobile Market. Journal of Global Marketing, 2009. 22(3): p. 199-215.

9. Leurent, F. and E. Windisch, Triggering the development of electric mobility: a review of public policies. European Transport Research Review, 2011. 3(4): p. 221-235.

10. Xinhua. China to become world's largest market for new energy vehicles. 2015

11. Celine Cluzel, B.L., Eleanor Standen, Pathways to high penetration of electric vehicles, T.c.o.o.c. change, Editor. 2013.

12. JUNG-Soo Yi and S. PARK, Cross-Cultural Differences in Decision-Making Styles_A Style of College Students in Five Countries.pdf. Social Behavior and Personality, 2003. 31(1): p. 35-48.

13. Jamal, Z.B., Cross-cultural Impact on Marketing Strategies: A Study on Automobile Industry. International Conference on Business, Law and Corporate Social Responsibility, 2014. (ICBLCSR'14). 14. Axsen, J. and K.S. Kurani, Hybrid, plug-in hybrid, or electric - What do car buyers want? Energy Policy, 2013. 61: p. 532-543.

15. Zhen, W., The Strategy of EVs Large Scale Penetration in Shenzhen. Auto Review(Chinese), 2014. 16. Bunce, L., M. Harris, and M. Burgess, Charge up then charge out? Drivers' perceptions and experiences of electric vehicles in the UK. Transportation Research Part A: Policy and Practice, 2014. 59: p. 278-287.

17. Kim, J., S. Rasouli, and H. Timmermans, Expanding scope of hybrid choice models allowing for mixture of social influences and latent attitudes: Application to intended purchase of electric cars. Transportation Research Part A: Policy and Practice, 2014. 69: p. 71-85.

18. Dimitropoulos, A., P. Rietveld, and J.N. van Ommeren, Consumer valuation of changes in driving range: A meta-analysis. Transportation Research Part A: Policy and Practice, 2013. 55: p. 27-45.

19. Skippon, S.M., How consumer drivers construe vehicle performance: Implications for electric vehicles. Transportation Research Part F: Traffic Psychology and Behaviour, 2014. 23: p. 15-31.

20. Higgins, A., et al., Combining choice modelling and multi-criteria analysis for technology diffusion: An application to the uptake of electric vehicles. Technological Forecasting and Social Change, 2012. 79(8): p. 1399-1412.

21. van Vliet, O.P.R., et al., Techno-economic comparison of series hybrid, plug-in hybrid, fuel cell and regular cars. Journal of Power Sources, 2010. 195(19): p. 6570-6585.

22. Hirte, G. and S. Tscharaktschiew, The optimal subsidy on electric vehicles in German metropolitan areas: A spatial general equilibrium analysis. Energy Economics, 2013. 40: p. 515-528.

23. Krause, R.M., et al., Perception and reality: Public knowledge of plug-in electric vehicles in 21 U.S. cities. Energy Policy, 2013. 63: p. 433-440.

24. Lebeau, K., Consumer attitudes toward battery electric vehicles: A large scale survey. 2013.

25. Graham-Rowe, E., et al., Mainstream consumers driving plug-in battery-electric and plug-in hybrid electric cars: A qualitative analysis of responses and evaluations. Transportation Research 
Part A: Policy and Practice, 2012. 46(1): p. 140-153.

26. Al-Alawi, B.M. and T.H. Bradley, Total cost of ownership, payback, and consumer preference modeling of plug-in hybrid electric vehicles. Applied Energy, 2013. 103: p. 488-506.

27. Franke, T. and J.F. Krems, Understanding charging behaviour of electric vehicle users. Transportation Research Part F: Traffic Psychology and Behaviour, 2013. 21: p. 75-89.

28. Azadfar, E., V. Sreeram, and D. Harries, The investigation of the major factors influencing plug-in electric vehicle driving patterns and charging behaviour. Renewable and Sustainable Energy Reviews, 2015. 42: p. 1065-1076.

29. Steinhilber, S., P. Wells, and S. Thankappan, Socio-technical inertia: Understanding the barriers to electric vehicles. Energy Policy, 2013. 60: p. 531-539.

30. Lane, B. and S. Potter, The adoption of cleaner vehicles in the UK: exploring the consumer attitude-action gap. Journal of Cleaner Production, 2007. 15(11-12): p. 1085-1092.

31. Dijk, M., R.J. Orsato, and R. Kemp, The emergence of an electric mobility trajectory. Energy Policy, 2013. 52: p. 135-145.

32. Axsen, J. and K.S. Kurani, Anticipating plug-in hybrid vehicle energy impacts in California: Constructing consumer-informed recharge profiles. Transportation Research Part D: Transport and Environment, 2010. 15(4): p. 212-219.

33. Sierzchula, W., Factors influencing fleet manager adoption of electric vehicles. Transportation Research Part D: Transport and Environment, 2014. 31: p. 126-134.

34. Rolim, C.C., et al., Impacts of Electric Vehicle Adoption on Driver Behavior and Environmental Performance. Procedia - Social and Behavioral Sciences, 2012. 54: p. 706-715.

35. Zhou, Y., et al., Plug-in electric vehicle market penetration and incentives: a global review. Mitigation and Adaptation Strategies for Global Change, 2014. 20(5): p. 777-795.

36. Ziegler, A., Individual characteristics and stated preferences for alternative energy. 2010.

37. Klöckner, C.A., The dynamics of purchasing an electric vehicle - A prospective longitudinal study of the decision-making process. Transportation Research Part F: Traffic Psychology and Behaviour, 2014. 24: p. 103-116.

38. Liu, J. and G. Santos, Plug-In Hybrid Electric Vehicles' Potential for Urban Transport in China: The Role of Energy Sources and Utility Factors. International Journal of Sustainable Transportation, 2014. 9(2): p. 145-157.

39. Karplus, V.J., S. Paltsev, and J.M. Reilly, Prospects for plug-in hybrid electric vehicles in the United States and Japan: A general equilibrium analysis. Transportation Research Part A: Policy and Practice, 2010. 44(8): p. 620-641.

40. $\mathrm{Wu}, \mathrm{T}$., et al., Setting up charging electric stations within residential communities in current $\mathrm{China}$ : Gaming of government agencies and property management companies. Energy Policy, 2015. 77: p. 216-226.

41. Faria, R., et al., A sustainability assessment of electric vehicles as a personal mobility system. Energy Conversion and Management, 2012. 61: p. 19-30.

42. Pasaoglu, G., et al., Travel patterns and the potential use of electric cars - Results from a direct survey in six European countries. Technological Forecasting and Social Change, 2014. 87: p. 51-59.

43. Burgess, M., et al., Electric vehicle drivers' reported interactions with the public: Driving stereotype change? Transportation Research Part F: Traffic Psychology and Behaviour, 2013. 17: p. 33-44. 


\section{Contents}

$\begin{array}{llr}1 & \text { Introduction } & 1\end{array}$

2 Material and Methods $\quad 2$

3 Data and Control $\quad 3$

4 results $\quad 3$

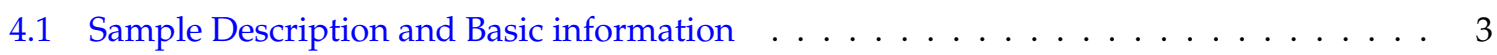

4.2 The Preference for EVs . . . . . . . . . . . . . . . . . . . . . 5

4.3 Consumers Purchasing Willingness and Attitude . . . . . . . . . . . . . . . . . . . . . . . .

4.4 Public Policy and Price Incentive . . . . . . . . . . . . . . . . . . . . . 15

5 Discussion $r$

5.1 Preference for EVs . . . . . . . . . . . . . . . . . . . . . . . 19

5.2 Consumers Purchasing Willingness and Attitude . . . . . . . . . . . . . . . . . . . . . 19

5.3 Public Policy and Price Incentive . . . . . . . . . . . . . . . . . . . . . . . 19

6 Conclusions $r$

\section{List of Figures}

Tab. 1 Brand Preference Analysis Demographic . . . . . . . . . . . . . . . . . 5

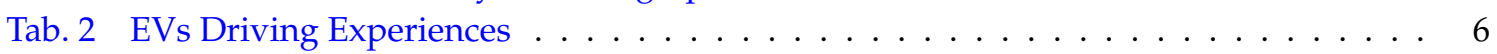

Tab. 3 Regression Residual Distribution .................... 8

Tab. 4 Willingness of The First time Car Buyer . . . . . . . . . . . . . . . . . . 9

Tab. 5 Willingness of The Second time Car Buyer . . . . . . . . . . . . . . . . . . 9

Tab. 6 Willingness to buy EVs considering national energy safety . . . . . . . . . . . 10

Tab. 7 Purchasing Willingness Based on ICEVs Technology Improvement . . . . . . . . . . 11

Tab. 8 The Participants attitudes toward EVs . . . . . . . . . . . . . . . . 11

Tab. 9 The Participants insights of spread adoption of EVs in future . . . . . . . . . . . . . 12

Tab. 10 The regression standard residual of attitude toward EVs . . . . . . . . . . . . . 14

Tab. 11 The regression standard residual of purchasing willingness to EVs . . . . . . . . . . 14

Tab. 12 PHEVs purchasing Willingness Based on Incentives . . . . . . . . . . . . . . . . . . . . . . . . . . . . .

Tab. 13 EVs Purchasing Willingness Based on Inventives . . . . . . . . . . . . . . . . . 16

Tab. 14 Willingness Changed When Subsides Canceled by 2020 . . . . . . . . . . . . . . . 17

Tab. 15 Passengers EVs Yield Past Years . . . . . . . . . . . . . . . . . . . 17

\section{List of Tables}

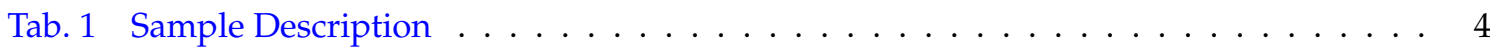

Tab. 2 Fisher Test Between Factors and Brand Preference . . . . . . . . . . . . . . 5

Tab. 3 Fisher Test Between Variables and EVs Driving Experiences . . . . . . . . . . . . . . . 6

Tab. 4 Factor Analysis Test of EVs Purchasing Preference . . . . . . . . . . . . . . 7

Tab. 5 Total Variance of Principal Components . . . . . . . . . . . . . . . . . 7

Tab. 6 Rotated Components Matrix . . . . . . . . . . . . . . . . . 7

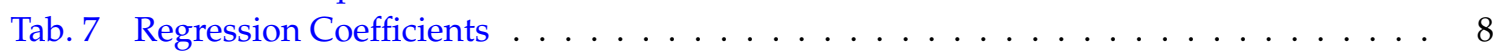

Tab. 8 Association Test for Willingness to Buy EVs . . . . . . . . . . . . . . . . . . 10

Tab. 9 KMO and Bartlett's Test . . . . . . . . . . . . . . . . . . . . . . . 12

Tab. 10 Total Variance Explained _. . . . . . . . . . . . . . . . . . . . . . . 12

Tab. 11 Rotated Component Matrixa . . . . . . . . . . . . . . . . . . . 13

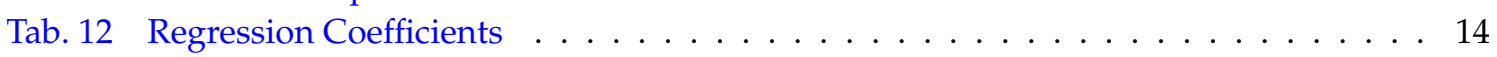




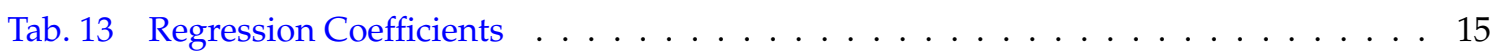

Tab. 14 EVs price subsides in China . . . . . . . . . . . . . . . . . . . . . . 15

Tab. 15 EVs price subsides in Shenzhen . . . . . . . . . . . . . . . . . . 15

Tab. 16 KMO and Bartlett's Test . . . . . . . . . . . . . . . . . . . . . . . . . . . . . . . . . . . . .

Tab. 17 Total Variance Explained _. . . . . . . . . . . . . . . . . . . . . 18

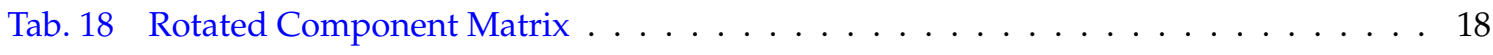

Tab. 19 Regression Coefficients . . . . . . . . . . . . . . . . . 18

(C) 2017 by the authors. Licensee Preprints, Basel, Switzerland. This article is an open access article distributed under the terms and conditions of the Creative Commons by Attribution (CC-BY) license (http://creativecommons.org/licenses/by/4.0/). 